\title{
Protective effect of quercetin and curcumin against cadmium-induced alterations in brain cortex and heart of rats
}

Chandrasinh N. Makwana, Urvesh D. Patel», S. Shreesha Rao, Vipul C. Ladumor, Chirag M. Modi and Harshad B. Patel Department of Veterinary Pharmacology and Toxicology, College of Veterinary Science and A.H., Kamdhenu University, Junagadh-362001, Gujarat, India

\section{Article Info}

Article history

Received 1 September 2021

Revised 19 October 2021

Accepted 20 October 2021

Published Online 30 December 2021

\section{Keywords}

Cadmium

Oxidative insult

Quercetin

Curcumin

Rats

Brain cortex

Heart

\begin{abstract}
Effects of combined treatment of quercetin $(50 \mathrm{mg} / \mathrm{kg}, \mathrm{PO})$ and curcumin $(100 \mathrm{mg} / \mathrm{kg}$, PO) against oxidative damage in the brain cortex and the heart of rats due to cadmium (Cd) (100 ppm in drinking water) were investigated. In the brain cortex of rats exposed to Cd, quercetin treatment improved the SOD activity and GSH level which resulted in lower level of MDA when given in combination with curcumin. Curcumin treatment also improved the SOD activity and the GSH level partially in brain cortex. In the heart, curcumin significantly enhanced the GSH stimulating effect of the quercetin which caused less Cdinduced lipid peroxidation. Plasma nitric oxide levels in rats treated with curcumin alone as well as quercetin and curcumin combination were significantly lower as compared to that of toxicity group. As compared to individual treatment of quercetin and curcumin, the combination of both agents produced marked protective effect against Cd-induced histopathological changes in brain cortex and heart of rats.
\end{abstract}

\section{Introduction}

Heavy metals are present in the environment which contaminates the natural resources. Health of humans and animals is affected by the entry of such heavy metals in the biological system. They enter in the body of humans or animals through respiratory and digestive systems as well as external exposure through skin and cause adverse health effects. Most organs are affected by heavy metals upon acute exposure at high dose or sub-acute exposure at lower dose. The reactive nitrogen and oxygen species are produced by heavy metals upon reaction to macromolecules in the body and the toxicity occurs primarily due to oxidative stress (Flora et al., 2008) which leads to cellular oxidative damage in majority of organs (Sengupta, 2002).

Cadmium $(\mathrm{Cd})$ is the metal present in the environment as a natural compound and also concentrated at various places due to industry work as well as cigarette smoke (WHO, 1992; Zalups and Ahmad, 2003). Organs like heart, brain, kidneys, liver, lungs, bones, hematopoietic organs; endocrine and reproductive organs are affected by long term exposure to Cd (Rao et al., 2019; Satarug et al., 2010; Cuypers et al., 2010; Makwana et al., 2019; Patel et al., 2021). Amongst them, the brain is very sensitive to oxidative stress (Cooper, 1907). Cadmium causes neurological disturbances along with alteration to acetylcholinesterase (AChE) activity (Viaene et al., 2000). Blood pressure, high prevalence of heart affection and increased

Corresponding author: Dr. Urveshkumar D. Patel Associate Professor, Department of Veterinary Pharmacology and Toxicology, College of Veterinary Science and A.H., Junagadh, Kamdhenu University, Junagadh-362001, Gujarat, India E-mail: urvesh1981@yahoo.com

Tel.: +91-9725003818

Copyright (c) 2021 Ukaaz Publications. All rights reserved.

Email: ukaaz@yahoo.com; Website: www.ukaazpublications.com cardiac output may be the result of Cd exposure (Kopp et al., 1982; Mennear, 1979). The key role of flavonoids and other phytochemicals have been studied for having their role in prevention of damage caused by continuous exposure to metal (Patel et al., 2020).

Amongst flavonoids, quercetin (QE) is known for having various pharmacological activities like antiviral, anticancer, antioxidant, antimicrobial, anti-inflammatory and many more (Maalik et al., 2014). Quercetin is present in many plants especially onion, tea, apple with skin, broccoli, green tea and red wine (Manach et al., 2005). It is capable of scavenging reactive oxygen species (ROS) (Boots et al., 2008). It is useful in cardiovascular and metabolic diseases as it has anti-inflammatory and antidiabetic activities (Russo et al., 2012; Kotadiya et al., 2018). It has the ability to cross the blood-brain barrier but the amount entering in the brain may be less (Costa et al., 2016). Quercetin through intraperitoneal administration showed beneficial effects against the neurotoxicity caused by subcutaneously injected Cd in rats (Unsal et al., 2013).

Curcumin is another important phytoconstituent which has an important role in medicine. Curcumin is a yellowish dye derived from Curcuma longa. Curcuma longa has been used traditionally in India and other countries since long back. Curcumin demonstrated antineoplastic, anti-mutagenic, anti-inflammatory and antioxidant activates (Naiket al., 2004). It has superoxide, hydroxyl radical and the nitrogen dioxide scavenging property (Daniel et al., 2004). Curcumin showed neuroprotective (Aggarwal and Harikumar 2009) and cardioprotective (Mohanty et al., 2004) effects along with protection to testes (Ilbey et al., 2009).

Many studies have been carried out to demonstrate the protective role of quercetin or curcumin against heavy metal-induced toxicity 
particularly Cd toxicity in laboratory animals. However, the study pointing towards evaluation of potency of quercetin and curcumin in combination against oxidative stress to brain cortex and heart following low dose subacute $\mathrm{Cd}$ exposure has not been reported so far. Thus, the present study was planned to evaluate the role of both active phytoconstituents in combination against $\mathrm{Cd}$-induced oxidative stress mediated pathophysiological alterations in brain cortex and heart of rats.

\section{Materials and Methods}

\subsection{Chemicals}

Cadmium chloride (Himedia, Mumbai), quercetin, curcumin (Sigma Aldrich, USA), potassium dihydrogen phosphate, sodium hydrogen phosphate (S.D. Fine, Mumbai), dTNB, RBC lysis buffer, pyro- gallol, acetylthiocholine iodide, Bradford reagent (Sigma Aldrich, USA), hydrogen peroxide and ethylenediaminetetra acetic acid (Merck Ltd., Mumbai) and other chemicals of analytical grade were used in the study.

\subsection{Experimental animals and treatment}

Thirty-six SD male rats were used in the study (8-9 weeks, 290$350 \mathrm{~g}$ ). Feed and water were supplied ad libitum during the study period. Rats were kept in a controlled environment (Temperature range between $23-27^{\circ} \mathrm{C}$; relative humidity: $42-54 \% ; 12$ hours light dark cycle). The rats were randomly divided into 6 groups and different treatments were given to animals for a period of 28 days (Table 1). The experiment was approved by the Animal Ethics Committee of the Institute (No. JAU/JVC/ IAEC/SA/32/18).

Table 1: Treatment groups and types of different treatments given to animals

\begin{tabular}{|l|l|}
\hline Groups(n=6) & Treatment for 28 days \\
\hline $\mathrm{C} 1$ (Normal control) & Normal drinking water $(\mathrm{RO}$ water $)$ \\
$\mathrm{C} 2$ (Toxicity control) & $\mathrm{CdCl}_{2}(100 \mathrm{ppm}$ in drinking water $)$ \\
$\mathrm{C} 3$ (Vehicle control) & $\mathrm{CdCl}_{2}(100 \mathrm{ppm}$ in drinking water $)+$ Vehicle $($ Corn oil, PO $)$ \\
$\mathrm{T} 1$ (Treatment 1$)$ & $\mathrm{CdCl}_{2}(100 \mathrm{ppm}$ in drinking water $)+$ Quercetin $(50 \mathrm{mg} / \mathrm{kg}, \mathrm{PO})$ \\
$\mathrm{T} 2$ (Treatment 2$)$ & $\mathrm{CdCl}_{2}(100 \mathrm{ppm}$ in drinking water $)+$ Curcumin $(100 \mathrm{mg} / \mathrm{kg}, \mathrm{PO})$ \\
$\mathrm{T} 3$ (Treatment 3$)$ & $\mathrm{CdCl}_{2}(100 \mathrm{ppm}$ in drinking water $)+$ Quercetin $(50 \mathrm{mg} / \mathrm{kg}, \mathrm{PO})+$ Curcumin $(100 \mathrm{mg} / \mathrm{kg}, \mathrm{PO})$ \\
\hline
\end{tabular}

Table 2: Body weight gain (g/rat/week) in experimental animals of different groups

\begin{tabular}{|c|c|c|c|c|}
\hline Group & Day $7($ Mean \pm SE $)$ & Day $14($ Mean \pm SE $)$ & Day 21 $($ Mean \pm SE $)$ & Day 28 $($ Mean \pm SE) \\
\hline C1 & $35.67 \pm 2.24^{\mathrm{b}}$ & $38.87 \pm 6.27^{\mathrm{b}}$ & $29.62 \pm 2.75^{\mathrm{a}}$ & $22.38 \pm 1.91^{\mathrm{abc}}$ \\
C2 & $34.93 \pm 3.19^{\mathrm{ab}}$ & $30.43 \pm 3.08^{\mathrm{ab}}$ & $36.27 \pm 4.06^{\mathrm{a}}$ & $14.43 \pm 2.74^{\mathrm{a}}$ \\
C3 & $21.30 \pm 4.34^{\mathrm{ab}}$ & $31.20 \pm 3.27^{\mathrm{ab}}$ & $32.50 \pm 2.31^{\mathrm{a}}$ & $20.95 \pm 2.04^{\mathrm{ab}}$ \\
T 1 & $18.62 \pm 2.75^{\mathrm{a}}$ & $17.58 \pm 3.03^{\mathrm{a}}$ & $29.43 \pm 4.15^{\mathrm{a}}$ & $26.73 \pm 0.91^{\mathrm{bc}}$ \\
T 2 & $25.87 \pm 2.25^{\mathrm{ab}}$ & $31.48 \pm 4.99^{\mathrm{ab}}$ & $30.22 \pm 2.61^{\mathrm{a}}$ & $16.65 \pm 2.60^{\mathrm{ab}}$ \\
T 3 & $32.57 \pm 9.42^{\mathrm{ab}}$ & $19.30 \pm 5.02^{\mathrm{a}}$ & $32.00 \pm 8.05^{\mathrm{a}}$ & $34.12 \pm 4.56^{\mathrm{c}}$ \\
\hline
\end{tabular}

Values with different superscript in a column differ significantly $(p<0.05)$

\subsection{Collection of samples}

Animals were humanely sacrificed at the end of experiment to observe gross pathological changes in both organs and collect the samples for evaluation of oxidative stress markers. The organ samples were collected in a cold phosphate buffer $(10 \% ; 7.5 \mathrm{pH})$ and homogenate was prepared. The homogenate was centrifuged at $12000 \mathrm{~g}$ for $5 \mathrm{~min}\left(4^{\circ} \mathrm{C}\right)$. The supernatant was used for estimation of various antioxidant enzymes except for SOD for that Tris-EDTA buffer $(8.5 \mathrm{pH})$ was used and centrifuged at $12000 \mathrm{~g}$ for $40 \mathrm{~min}\left(4^{\circ} \mathrm{C}\right)$. Protein content in each tissue sample was estimated (Bradford, 1976) and the data was used to calculate catalase activity in organ tissues. Cortex part of the brain was also collected in a phosphate buffer $\left(\mathrm{PB}: \mathrm{KH}_{2} \mathrm{PO}_{4}\right.$ and $\mathrm{Na}_{2} \mathrm{HPO}_{4} \times$ $2 \mathrm{H}_{2} \mathrm{O} \mathrm{pH} \mathrm{8.0,0.01M)} \mathrm{for} \mathrm{estimation} \mathrm{of} \mathrm{acetylcholinesterase} \mathrm{activity.}$ The tissues of brain cortex and heart of all animals were collected in $10 \%$ formalin for histopathological examination.

\subsection{Body weight gain}

During the experimental period, body weight of rats was recorded daily and per week body weight gain was calculated.

\subsection{Oxidative stress parameters in tissue}

SOD and catalase activity in tissue were estimated according to the previously published methods (Marklund and Marklund, 1974; Aebi et al., 1974). The GSH level in tissue was estimated according to standard method (Ellman, 1959). The level of malondialdehyde (MDA) was measured with the standard kit (Sigma Aldrich, Germany).

\subsection{Acetylcholinesterase activity in brain cortex}

The acetylcholinesterase activity was measured with a previously reported method (Ellman et al., 1961).

\subsection{Plasma nitric oxide level}

Nitric oxide level was assessed on the basis of its stable oxidation end-products nitrate and nitrite assay (Slid and Horak, 2009).

\subsection{Histopathology}

The standard steps of formalin fixation and paraffin embedding were followed. The section cutting (5-6 $\mu$ thickness) was performed with 
a semi-automated rotary microtome (Leica Biosystems, Germany). Each section was stained with hematoxylin and eosin stain (Luna, 1968). All slides were observed for microscopic pathological lesions.

\subsection{Statistical analysis}

Data were analyzed by one-way ANOVA followed by Tukey's HSD test to observe the difference among the treatments. The $p<0.05$ was considered as statistically significant and $p<0.01$ was considered highly significant.

\section{Results}

\subsection{Body weight gain}

In the present study, body weight gain in rats of the toxicity group was significantly $(p<0.05)$ lowered during the $4^{\text {th }}$ week as compared to that of control animals (Table 2). Quercetin showed a positive effect on body weight gain but curcumin treatment was inefficient to produce such an effect. However, curcumin enhanced the effect of quercetin pertaining to maintenance of body weight gain during the $\mathrm{Cd}$ exposure as rats treated with quercetin + curcumin had shown highest body weight gain.

\subsection{Oxidative stress parameters in brain cortex}

The SOD and catalase activity, GSH and MDA level in brain cortex collected from animals of all groups are presented in Figure 1. The SOD and CAT activity as well as GSH content in brain cortex of Cdtreated rats were non-significantly lower. The MDA level in the brain cortex was also non-significantly higher in toxicity and vehicle-treated groups as compared to that of the normal control group (C1). Quercetin treatment was able to improve the SOD activity $(p<0.05)$, CAT activity and GSH level $(p>0.05)$. The curcumin treated rats exhibited highest level of SOD activity. Quercetin and curcumin combined treatment resulted in lowest level of MDA which was at par to the level of MDA in the brain cortex of normal control rats.
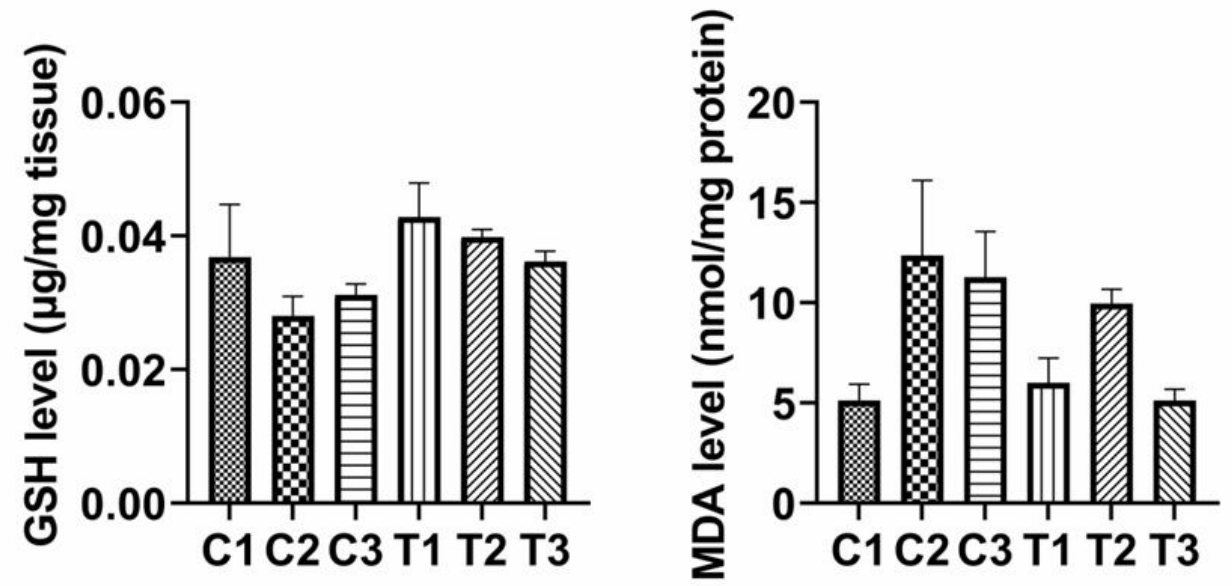

Figure 1: Status of oxidative stress markers in brain cortex of $\operatorname{rats}(*: p<0.05, * *: p<0.01)$. 

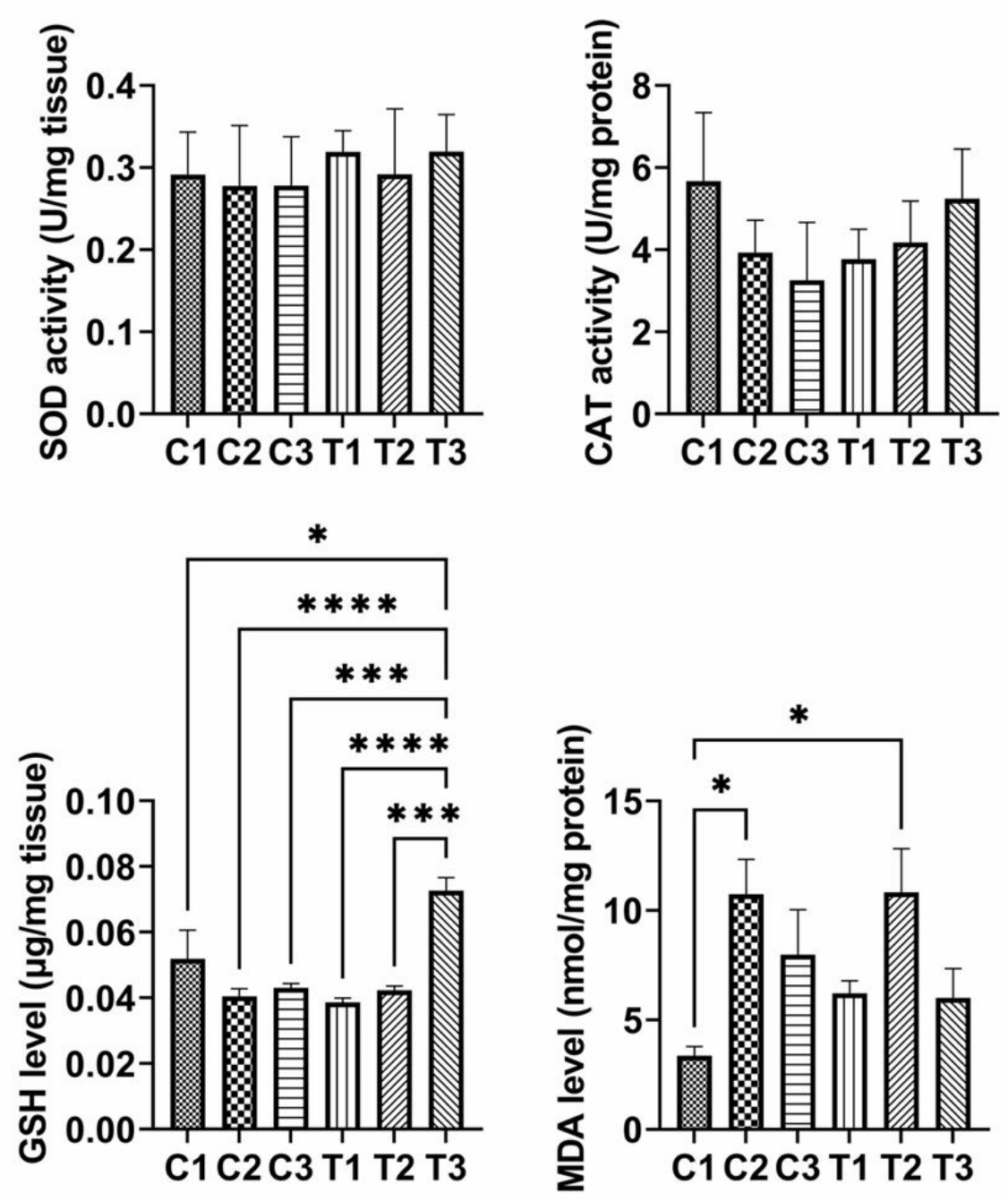

Figure 2: Status of oxidative stress markers in cardiac tissue of rats $(*: p<0.05, * * *: p<0.005, * * * *$ : $p<0.001)$.
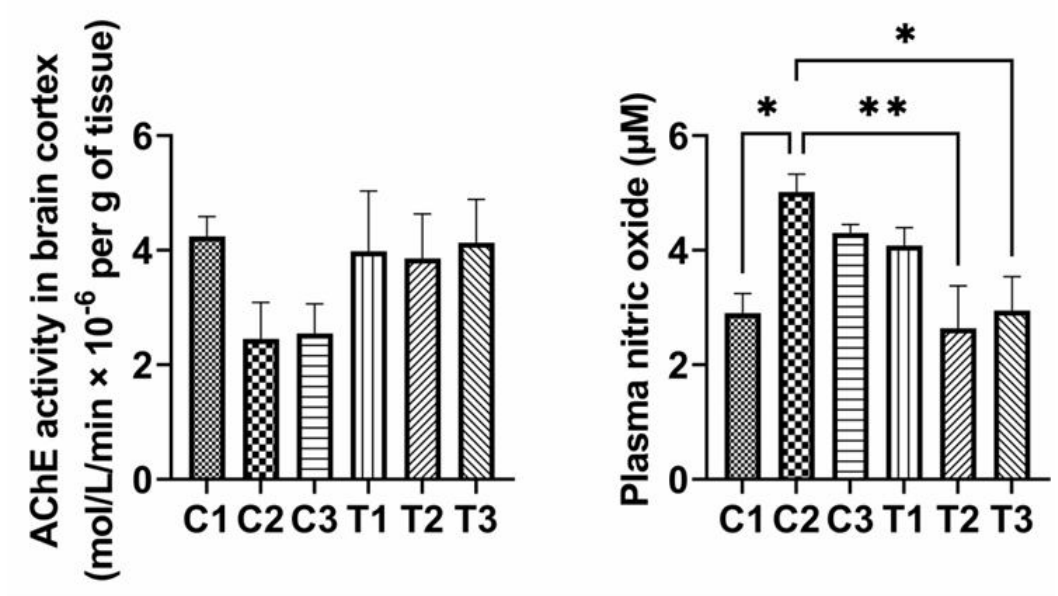

Figure 3: AChE activity in brain cortex and nitric oxide level in plasma of rats $(*: p<0.05, * *: p<0.01)$. 


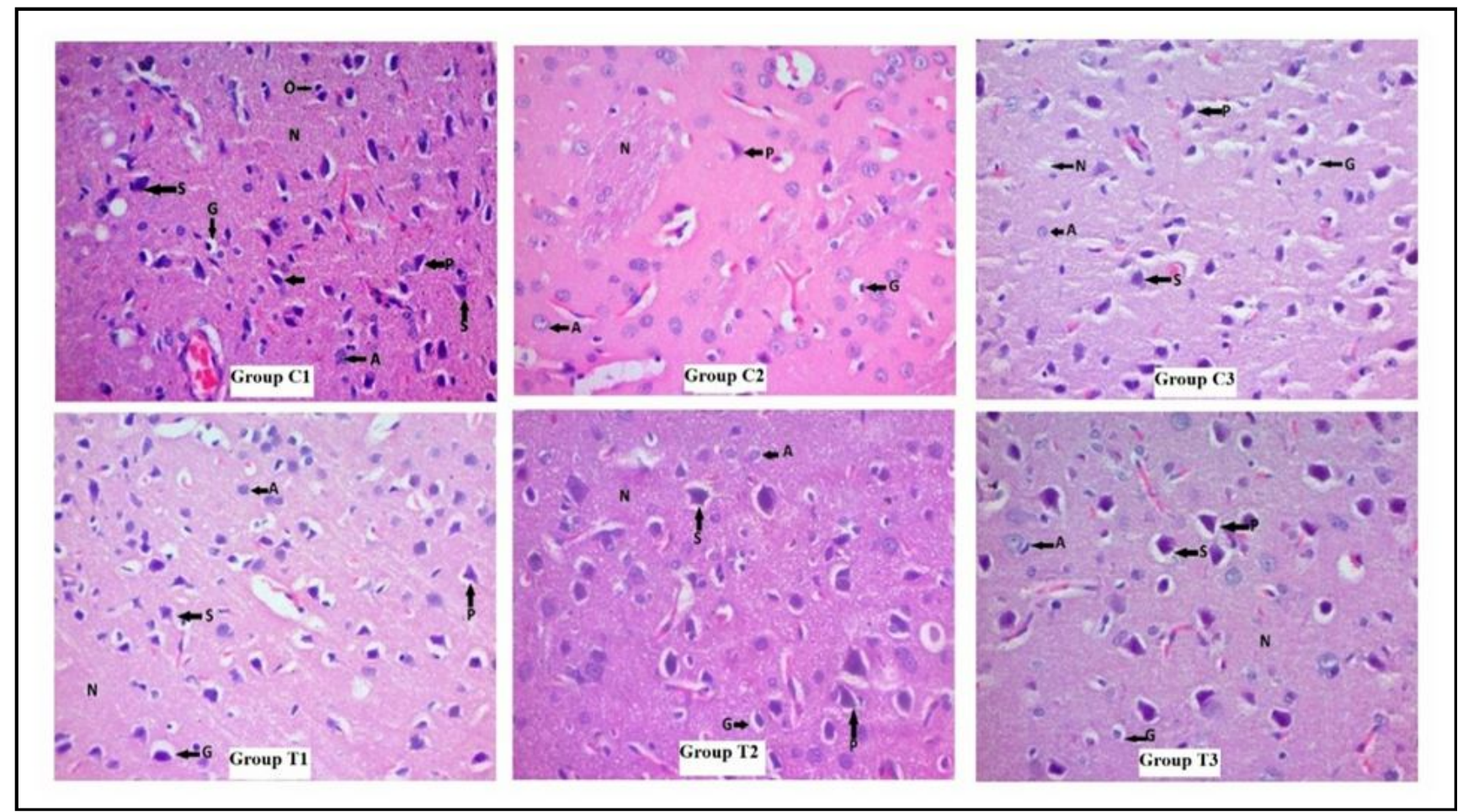

Figure 4: Microscopic changes in cerebral cortex of rats under different treatment groups $($ H \& E staining, $\times$ 400) Group C1: Normal histological architecture with astrocytes (A), pyramidal cell $(\mathbf{P})$, stellate cells $(\mathrm{S})$, oligodendrocytes $(\mathbf{O})$, microglia (M), neuropil (N); Group C2: Vacuolated neuropil (N), irregular shape of pyramidal cells (P) with increase surrounding space, and swollen astrocytes (A) with irregular shape, pyknotic glial cells (G) as compared to normal control group; Group C3: Normal stellate cells (S), vacuolated neuropil (N), irregular shape of pyramidal cells (P) with increase surrounding space, and swollen astrocytes (A) with irregular shape, pyknotic glial cells (G) cytotoxic oedema in brain capillary compared to normal control; Group T1: Less vacuolation in neuropil (N), normal pyramidal cells (P) and stellate cells (S) with slight increased surrounding space, and mild swelling in astrocytes (A), pyknotic glial cells (G) as compared to toxicity control group; Group T2: Mild degeneration in neuropil (N), normal pyramidal (P) and stellate cells (S), and mild swelling in astrocytes (A), pyknotic glial cells (G) as compared to toxicity control group; Group T3: Normal neuropil (N) with normal pyramidal cells (P), astrocytes (A), stellate cells (S), glial cell (G) without extracellular vacuolation as compared to toxicity control group.

\subsection{Oxidative stress parameters in cardiac tissue}

The SOD and catalase activity, GSH and MDA level in cardiac tissue collected from animals of all groups are presented in Figure 2. The SOD activity in cardiac tissue of rats of all groups were not significantly differ from each other. While, CAT activity in cardiac tissue was non-significantly decreased in toxicity and vehicle-treated groups as compared to that of the normal control group. The level of GSH and MDA in cardiac tissue of rats of toxicity group was non-significantly lower and higher, respectively as compared to that of the normal control group. CAT activity in cardiac tissue has shown improvement in rats treated with quercetin and curcumin in combination. The GSH level was significantly higher in combined treatment group as compared to that of toxicity group. The cadmium treatment significantly increased the level of MDA in cardiac tissue. The quercetin treatment only was able to reduce the level of MDA in cardiac tissue. The GSH stimulating effect produced by the quercetin might be responsible for less lipid peroxidation in the hearts of animals exposed to $\mathrm{Cd}$. The level of MDA in cardiac tissue of rats treated with quercetin and quercetin + curcumin was parallel to normal control rats which indicates the effect might be due to quercetin rather than curcumin.

\subsection{Acetylcholinesterase activity in brain cortex}

The activity of AchE in brain cortex tissues collected from all rats is depicted in Figure 3. The AchE activity in the brain cortex was partially decreased in toxicity and vehicle-treated groups as compared to that of the normal control group. The activity of AChE in the brain cortex of rats all treatment groupswere at par with that of normal control rats.

\subsection{Plasma nitric oxide level}

Nitric oxide levels in plasma samples collected from all animals are presented in Figure 3. The plasma nitric oxide level was significantly increased in toxicity group and non-significantly in vehicle group as compared to that of the normal control group. The plasma nitric oxide levels in animals treated with curcumin as well as quercetin + curcumin was lower $(p<0.05)$ but not in quercetin-treated rats as compared to toxicity group.

3.6 Histopathological changes in brain cortex and cardiac tissue

Microscopic changes in the brain cortex of rats of different treatment groups are depicted in Figure 4. Microscopic changes in the cardiac tissue of rats of different treatment groups are depicted in Figure 5. 


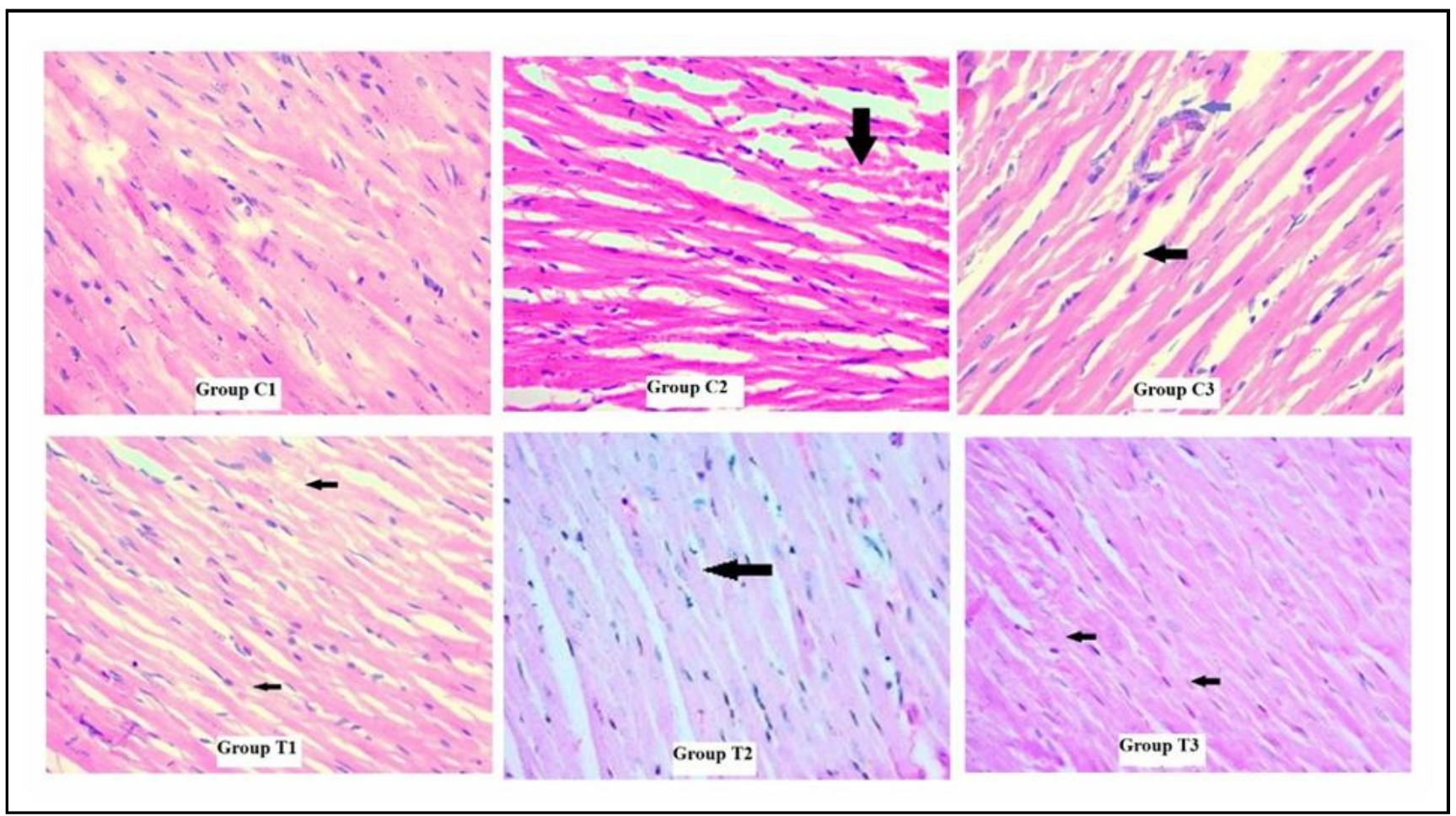

Figure 5: Microscopic changes in cardiac tissue of rats under different treatment groups $(400 \mathrm{X}, \mathrm{H} \& \mathrm{E}$ staining) Group C1: Normal and organized cardiac muscle fibers; Group C2: Degeneration with irregular arrangement of muscle fibers (black arrow) as compared to normal control; Group C3: Degeneration with irregular arrangement of muscle fibers (black arrow) and vascular congestion (blue arrow) as compared to normal control; Group T1: Slight degeneration of muscle fibers as well as near to normal pattern of arrangement of muscle fibers as compared to toxicity control; Group T2 and T3: Slight degeneration of muscle fibers with improved arrangement of muscle fibers as compared to toxicity control.

\section{Discussion}

Heavy metal like cadmium enters the body and may remain for a longer time in the body. Cadmium has a tendency to accumulate in the organs. Cadmium alters the cellular defense system particularly due to generation of reactive species which generally cause the activation of mitogen activated protein kinase and c-Jun N-terminal kinase. Such changes down-regulates the gene responsible for defense system and repair mechanism in the cells (Hussain et al., 1987). It has been reported that cadmium affects the brain endothelial cell in vitro through oxidative stress (Tobwala et al., 2014). Rats exposed to $\mathrm{Cd}$ at 200 and $300 \mathrm{ppm}$ level for 6 weeks showed significant dose dependent decrease in brain SOD activity (Oguninola et al., 2016). However, in the present study, exposure to Cd for 4 weeks might alter the SOD activity in the initial stage but low dose exposure for 4 weeks to $\mathrm{Cd}$ might stimulate the adoptive changes in the body which may be the reason for not altering the SOD activity. Curcumin alone and in combination with quercetin showed stimulating effect on SOD activity which indicates that both the compounds, particularly curcumin more efficiently counteracted the oxidative insult caused by $\mathrm{Cd}$. In an earlier report, $\mathrm{Cd}$ administration at $0.4 \mathrm{mg} / \mathrm{kg}$ for 30 days in rats has been reported to cause significant reduction of GSH level in different part of the brain. GSSG is reduced to GSH by glutathione reductase and GPDH supplies the NADPH required for this reaction. The inhibition of glutathione reductase and GPDH enzymes is responsible for level of glutathione
(Shukla et al., 1988). In the present study, Cd might cause the effect on GSH in early stage but in later stage during the sub-acute exposure showed near to normalized activity. However, an increased level of MDA was observed in rats of toxicity group indicates that $\mathrm{Cd}$ exposure resulted lipid peroxidation in the brain cortex. Higher level of oxygen utilization and much amount of polyunsaturated fatty acids, the brain is susceptible for lipid peroxidation (Calabrese et al., 2000). Increased MDA levels with altered oxidative stress markers, and neuronal apoptosis caused by $\mathrm{Cd}$ at higher dose were reported to be protected by quercetin (Unsal et al., 2013) which indicates that quercetin has ability to protect the brain from Cd-induced damage. In the present study, quercetin treatment showed reduction in MDA level, but curcumin exhibited slight reduction of MDA as compared to toxicity group which might be due to less bioavailability and penetration of curcumin through blood brain barrier. The antioxidant effect of curcumin is due to the scavenging of superoxide and hydroxyl radicals and the ability to inhibit various oxidases (Grisham and McCord, 1986). Curcumin has reported to have positive effect on the level of GSH and SOD and slightly decreased the level of MDA in colon cancer and Parkinson's disease which is indication of ability of curcumin to eliminate the singlet oxygen and nitric oxide (Rao et al., 1995; Siddique et al., 2014). In our study, increased plasma nitric oxide level by $\mathrm{Cd}$ exposure was also normalized by curcumin treatment and partially by quercetin which justifies the effect of curcumin and quercetin against lipid peroxidation. 
The lower antioxidant enzyme activity and the level of glutathione make the myocardium more sensitive for oxidative insult (Meister and Anderson, 1991; Wendell, 1990). In the present study, improved CAT activity was noticed in the hearts of animals treated with quercetin along with curcumin as compared to that of the toxicity group.

Over-expression of metallothionein and glutathione following longterm $\mathrm{Cd}$ exposure is responsible for adaptive mechanisms which reduces the $\mathrm{Cd}$-induced oxidative stress. Acquired $\mathrm{Cd}$ tolerance with aberrant gene expression plays an important role in chronic $\mathrm{Cd}$ toxicity (Patra et al., 2011). However, ROS generated following acute $\mathrm{Cd}$ toxicity play a key role in the tissue damage.

Heavy metals produce the neurotoxicity along with alteration of the activity of AchE. One of important reasons for low AchE activity in the brain is the higher level of free radicals which alter the cholinergic pathway (Tsakiris et al., 2000). In the present study, AchE activity was partially decreased due to cadmium exposureat low dose for longer duration of time which might be responsible for development of tolerance as a part of the body's defense mechanism. Generally, metal-induced cholinergic symptoms occur as level of acetylcholine increases because of decreased activity of AchE. However, alteration in AchE by $\mathrm{Cd}$ in the present experiment was not sufficient to cause cholinergic symptoms in animals. As a result of prevention of $\mathrm{Ca}^{2+}$ influx through membrane channels into the nerve terminal, $\mathrm{Cd}$ exposure alters the release of neurotransmitters which ultimately leads to symptoms of neurotoxicity (Antonio et al., 2002). It has been reported that quercetin treatment prevented alterations in the AChE activity in all cerebral structures of rats through modulation of AchE activity following high dose of $\mathrm{Cd}$ exposure (Abdaalla et al., 2014). Curcumin has also been reported to have a positive effect on $\mathrm{AChE}$ as it increased its activity in rats exposed to aluminum (Kumar et al., 2009). In the present study, improvement in the activity of $\mathrm{AChE}$ in animals treated with alone and combination of quercetin and curcumin indicates ability of them to prevent Cd-induced alterations in the neurotransmission process in the nervous system.

The release of higher amount of nitric oxide (NO) following $\mathrm{Cd}$ exposure causes the changes in vascular system (Whittemore et al., 1991). Increased level of nitric oxide in Cd-induced oxidative damage (Chen et al., 2003) is due to upregulation of tumor necrosis factor alpha-mediated induction of nitric oxide synthase (Morris and Billiar, 1994). Peroxynitrite radical formed from the nitric oxide causes the cellular alterations (Clancy and Abramson, 1995). The increased level of NO in plasma or tissues due to metal like Cd causes the pathophysiological changes. In support of the finding of the present study, it has been also reported that $\mathrm{Cd}(6.5 \mathrm{mg} / \mathrm{kg}$ P.O. for 5 days $)$ significantly increased the nitric oxide level in the brain (Elkhadragy et al., 2018). In this study, quercetin did not significantly affect the level of plasma nitric oxide. However, in contrast to this finding, ElShafey et al. (2015) reported significantly reduced the level of nitric oxide in plasma by quercetin treatment in paracetamol-treated rats. They gave prior treatment of quercetin before administration of paracetamol and simultaneous administration of quercetin and cadmium in the present study indicated that pre-exposure to flavonoids may provide better protection. The nitric oxide lowering effect of quercetin is due to its ability to inhibit nitric oxide synthase (iNOS) (Dias et al., 2005; Jo et al., 2008). Curcumin treatment has been reported to reduce the plasma nitric oxide level in varicocele rats (Izadpanah et al., 2015) which supports the result obtained in the present study regarding significant nitric oxide lowering effect of curcumin.

Similar to our observations, Unsal et al. (2013) reported well preserved the normal histological architecture of the frontal cortex in Cd-exposed rats when treated with quercetin. Sarada et al. (2015) observed histopathological changes in brain cortex of rats under hypoxic condition and revealed the absence of oedema and inflammation in the brains of rats supplemented with curcumin. The findings of the present study are very well supported by previous studies that quercetin and curcumin have potential to ameliorate the oxidative stress mediated brain damage. In agreement with the present study, quercetin and curcumin pre-treatment also prevented histological changes produced by $\mathrm{Cd}$ and doxorubicin in heart, respectively (Prabhu et al., 2013; Swamy et al., 2012).

\section{Conclusion}

Cadmium exposure to rats at $100 \mathrm{ppm}$ level for 28 days caused oxidative stress mediated histopathological changes in brain cortex and heart. Nitric oxide plays an important role in the pathophysiological process caused by sub-acute cadmium exposure. Daily oral administration of quercetin along with curcumin in rats showed ameliorating effect against cadmium-induced alterations in brain cortex and heart. However, further study may be required to explore the role of nitric oxide in pathophysiological alterations following longterm low-level exposure to cadmium and possible cellular mechanism of protective action of both quercetin and curcumin.

\section{Acknowledgements}

Authors are highly thankful to Dr. D.T. Fefar, Dr. V. A. Kalaria, Department of Veterinary Pathology, Veterinary College, KU, Junagadh for his help during the study. Authors are also thankful to Dr. H.H. Savsani, Veterinary College, KU, Junagadh for providing necessary laboratory facilities to conduct the part of the study.

\section{Conflict of Interest}

The authors declare no conflicts of interest relevant to this article.

\section{References}

Abdalla, F.H.; Schmatz, R.; Cardoso, A.M.; Carvalho, F.B.; Baldissarelli, J.; de Oliveira, J.S.; Rosa, M.M.; GonçalvesNunes, M.A.; Rubin, M.A.; da Cruz, I.B.; Barbisan, F.; Dressler, V.L.; Pereira, L.B.; Schetinger, M.R.; Morsch, V.M.; Gonçalves, J.F. and Mazzanti, C.M. (2014). Quercetin protects the impairment of memory and anxiogenic-like behavior in rats exposed to cadmium: Possible involvement of the acetylcholinesterase and $\mathrm{Na}(+), \mathrm{K}(+)$-ATPase activities. Physiol. Behav., 135:152167.

Aebi, H.; Sonja, R.; Bernhard, S. and Frantisek, S. (1974). Heterogeneity of erythrocyte catalase $\Pi$, isolation and characterization of normal and variant erythrocyte catalase and their subunits. Eur. J. Biochem., 48(1): 137-145.

Aggarwal, B.B. and Harikumar, K.B. (2009). Potential therapeutic effects of curcumin, the anti-inflammatory agent, against neurodegenerative, cardiovascular, pulmonary, metabolic, autoimmune and neoplastic diseases. Intern. J. Biochem. Cell Biol., 41(1):40-59.

Antonio, M.T.; Lopenz, N. and Leret, M.I. (2002). Cadmium poisoning during development alters cerebellar and striatal function in rats. Toxicol., 176(1-2):59-66. 
Boots, A.W.; Haenen, GR. and Bast, A. (2008). Health effects of quercetin: From antioxidant to nutraceutical. Eur. J. Pharmacol. 585(2):325-337.

Bradford, M.M. (1976). A rapid and sensitive method for the quantitation of microgram quantities of protein utilizing the principle of protein-dye binding. Anal. Biochem.,72(1-2):248-254.

Calabrese, V.; Bates, T.E. and Stella, A.M.G. (2000). NO synthase and NO dependent signal pathways in brain aging and neurodegenerative disorders: the role of oxidant/antioxidant balance. Neurochem. Res., 25(9-10): 1315-1341.

Chen, L.; Zhou, J.; Gao, W. and Jiang, Y.Z. (2003). Action of NO and TNF alpha release of rats with cadmium loading in malfunction of multiple system organs. Acta Physiol. Sin., 55(5):535-540.

Clancy, R.M. and Abramson, S.B. (1995). Nitric oxide: a novel mediator of inflammation. Proc. Soc. Exp. Biol. Med., 210(2):93-101.

Cooper, J.J.L. (1997). Glutathione in the brain: disorders of glutathione metabolism, In: Barchi RL, Kunk LM (Eds.), The molecular and genetic basis of neurological disease, Butterworth-Heinemann, Boston, pp:1195-1230.

Costa, L.G.; Garrick, J. M.; Roque, P.J. and Pellacani, C. (2016). Mechanisms of neuroprotection by quercetin: Counteracting oxidative stress and more. Oxidative Med. Cellul. Longevity., pp:298-796

Cuypers, A.; Plusquin, M.; Remans, T.; Jozefczak, M.; Keunen, E.; Gielen, H.; Opdenakker, K.; Nair, A.R.; Munters, E.; Artois, T.J.; Nawrot, T.; Vangronsveld, J. and Smeets, K. (2010). Cadmium stress: An oxidative challenge. Biometals., 23(5):927-940.

Daniel, S.; Limson, J.L.; Dairam, A.; Watkins, G.M. and Daya, S. (2004). Through metal binding, curcumin protects against lead and cadmium-induced lipid peroxidation in rat brain homogenates and against leadinduced tissue damage in rat brain. J. Inorg. Biochem., 98(2):266275

Dias, A.S.; Porawski, M.; Alonso, M.; Marroni, N.; Collado, P.S. and GonzálezGallego, J. (2005). Quercetin decreases oxidative stress, NF-kappaB activation, and iNOS overexpression in liver of streptozotocininduced diabetic rats. J. Nutritions., 135(10):2299-2304.

Elkhadragy, M.F.; Kassab, R.B.; Metwally, D.; Almeer, R.; Abdel-Gaber, R.; AlOlayan, E.M.; Essawy, E.A.; Amin, H.K. and Abdel Moneim, A.E. (2018).Protective effects of Fragaria ananassa methanolic extract in a rat model of cadmium chloride-induced neurotoxicity. Biosci. Rep., 38(6):1-14.

Ellman, G (1959). Tissue sulfhydryl groups. Arch. Biochem. Biophy., 82(1):70-77.

Ellman, GL.; Courtney, K.D.; Valentino, J.R. and Featherstone, R.M.(1961). Anew and rapid colorimetric determination of acetylcholinesterase activity. Biochem. Pharmacol., 7(1):88-95.

El-Shafey, A.M.M.; Gamil, M.; Abd-Allah, A.; Ahmed, M.; Mohamadin, A.B.; Gamaleldin, I.; Harisa, A.C. and Mariee, A.D. (2015). Quercetin protects against acetaminophen-induced hepatorenal toxicity by reducing reactive oxygen and nitrogen species. Pathophysiol., 22(1):49-55.

Flora, S.J.S.; Megha, M. and Mehta, A. (2008). Heavy metal induced oxidative stress and its possible reversal by chelation therapy. The Ind. J. Med. Res., 12:501-523.

Grisham, M. and McCord, J. (1986). Chemistry and cytotoxicity of reactive oxygen metabolites, In: Taylor A Matalon S Ward P, editors. Physiology of oxygen radicals. Am Physiol Society, pp:1-18.

Hussain, T.; Shukla, G.S. and Chandra, S.F. (1987). Effects of cadmium on superoxide dismutase and lipid peroxidation in liver and kidney of growing rats, in vivo and in vitro studies. Pharmacol. Toxicol., 60(5):355-358
Ilbey, Y.O.; Ozbek, E.; Cekmen, M.; Simsek, A.; Otunctemur,A. and Somay,A. (2009). Protective effect of curcumin in cisplatin induced oxidative injury in rat testis: Mitogen-activated protein kinase and nuclear factorkappa B signaling pathways. Human Reprod., 24(7):1717-1725.

Izadpanah, M.; Alizadeh, R.; Minaee, M.B.; Heydari, L.; Babatunde, A. and Abbasi, M. (2015). The effects of curcumin on sperm parameters and nitric oxide production in varicocele rats. Intern. J. Morphol., 33(4):15301535 .

Jo, H.Y.; Kim, Y.; Nam, S.Y.; Lee, B.J.; Kim, Y.B.; Yun, Y.W. and Ahn, B. (2008). The inhibitory effect of quercetin gallate on iNOS expression induced by lipopolysaccharide in Balb/c mice. J. Vet. Sci., 9(3):267-272.

Kopp, S.J.; Glonek, T.; Perry, H.M.; Erlanger, M. and Perry, E.F. (1982). Cardiovascular action of cadmium at environmental exposure levels. Sci., 217(4562):837-839.

Kotadiya, C.R.; Patel, U.D.; Patel, H.B.; Modi, C.M. and Fefar, D.T. (2018). Evaluation of effects of Opuntia elatior Mill. fruit juice and quercetin on biochemical parameters and histopathological changes in diabetic rats. Ind. J. Trad. Know., 17(3):576-583.

Kumar, A.; Dogra, S. and Prakash, A. (2009). Protective effect of curcumin (Curcuma longa), against aluminium toxicity: Possible behavioral and biochemical alterations in rats. Behav. Brain Res., 205(2):384390 .

Luna, L.G. (1968). Routine staining procedures, hematoxylin and eosin stains, manual of histologic staining methods of the armed forces institute of pathology, (McGraw-Hill, New York), $3^{\text {rd }}$ edn., pp:32-39.

Maalik, A.; Khan, F.A.; Mumtaz, A.; Mehmood, A.; Azhar, S.; Atif, M.; Karim, S.; Altaf, Y. and Tariq, I. (2014). Pharmacological applications of quercetin and its derivatives: A short review. Trop. J. Pharmacol. Res., 13(9): 1561-1566.

Makwana, C.N.; Shreesha Rao S, Patel, U. D.; Patel, H. B., Modi, C. M. and Fefar, D.T.(2019). Status of oxidative stress in cerebral cortex and testes, acetylcholinesterase activity in cerebral cortex and sperm parameters in cadmium-exposed rats. Indian Journal of Animal Research, 20(54):820-828

Manach, C.; Williamson, G.; Morand, C.; Scalbert, A. and Remesy, C. (2005). Bioavailability and bioefficacy of polyphenols in humans; Review of bioavailability studies. The Am. J. Clin. Nutr., 81(1):230-242.

Marklund, S. and Marklund, G. (1974). Involvement of the superoxide anion radical in the autoxidation of pyrogallol and a convenient assay for superoxide dismutase. Eur. J. Biochemistry., 47(3):469-474.

Meister, A. and Anderson, M.E. (1991). Glutathione. Annual Rev. Biochem., 52(1):711-722.

Mennear, J.H. (1979). Cadmium Toxicity, Marcel Dekker, New York, $1^{\text {stedn. }}$ pp:61-158.

Mohanty, I.; Singh, A.D.; Dinda, A.; Joshi, S.; Talwar, K.K. and Gupta, S.K. (2004). Protective eûects of Curcuma longa on ischemia perfusion induced myocardial injuries and their mechanisms. Life Sci., 75(14):1701-1711.

Morris, S.M. and Billiar, T.R. (1994). New insights into the regulation of inducible nitric oxide synthesis. Am. J. Physiol., 266(6):829-839.

Naik, R.S.; Mujumdar, A.M. and Ghaskadbi, S. (2004). Protection of liver cells from ethanol cytotoxicity by curcumin in liver slice culture in vitro. J. Ethnopharmacol., 95(1):31-37.

Ogunrinola, O.O.; Wusu,D.A.; Fajana, O.O.; Olaitan, S.N.; Smith, Z.O. and AbdulRahman, I.B. (2016). Effect of low level cadmium exposure on superoxide dismutase activity in rat. Trop. J. Pharmaceut. Res., 15(1):115119.

Patel, U.D.; Bhatt,P. R., Pandya, K. B.; Patel H. B. and Modi, C. M. (2020).Cadmium induced oxidative stress-mediated pathophysiological alterations in chickens and their amelioration by polyherbal mixture enriched feed. Indian J. Trad. Knowled., 20(1):41-53. 
Patel, U.N.; Patel, U.D.;Khadayata, A.V.; Vaja, R.K.; Patel, H.B. and Modi C.M (2021). Assessment of neurotoxicity following single and co-exposure of cadmium and mercury in adult zebrafish: Behavior alterations, oxidative stress, gene expression, and histological impairment in brain. Water Air Soil Pollut., pp:232-340. https://doi.org/ 10.1007/s 1 1270-021-05274-1.

Patra, R.C.; Rautray, A.K. and Swarup, D. (2011). Oxidative stress in lead and cadmium toxicity and its amelioration. Vet. Med. Intern., 20:457327.

Prabhu, M.S.; Muthumani, M. and Shagirtha, K. (2013). Quercetin potentially attenuates cadmium induced oxidative stress mediated cardiotoxicity and dyslipidemia in rats. Eur. Rev. Med. Pharmacol. Sci., 17(5):582595 .

Rao, C.V.; Rivenson, A.; Simi, B. and Reddy, B.S. (1995). Chemoprevention of colon cancer by dietary curcumin. Annal. New York Acad. Sci., 768:201-204

Rao, S.S.; Makwana, C.N.; Patel, U.D.; Ladumor, V.C.; Patel, H.B. and Modi, C.M (2019). Oxidative stress mediated dose-dependent pathophysiological alterations in liver, kidney, heart and intestine of rats exposed to different levels of cadmium chloride. Int. J. Curr. Microbiol. Appl. Sci., 8(1):393-409,

Russo, M.; Spagnuolo, C.; Tedesco, I.; Bilotto, S. and Russo, G.L. (2012). The flavonoid quercetin in disease prevention and therapy: Facts and fancies. Biochem. Pharmacol., 83(1):6-15.

Sarada, S.K.S.; Titto, M.; Himadri, P.; Saumya, S. and Vijayalakshmi, V. (2015). Curcumin prophylaxis mitigates the incidence of hypobaric hypoxia-induced altered ion channels expression and impaired tight junction proteins integrity in rat brain. J. Neuro-inflamm., 12:118 .

Satarug, S.; Garrett, S.H.; Sens, M. A. and Sens, D.A. (2010). Cadmium, environment exposure and health outcomes. Environ. Health Persp., 118(2): 182-190.

Sengupta, A.K. (2002). Environmental separation of heavy metals: Engineering processes, $1^{\text {st }}$ dn, Lewis publishers, Boca Raton, FL, pp:114.

Shukla, G.S.; Srivastava, R.S. and Chandra, S.V. (1988). Glutathione status and cadmium neurotoxicity: studies in discrete brain regions of growing rats. Fund. Appl. Toxicol., 11(1):229-235.
Siddique, Y.H.; Naz, F. and Jyoti, S. (2014). Effect of curcumin on lifespan, activity pattern, oxidative stress, and apoptosis in the brains of transgenic drosophila model of Parkinson's disease. Bio. Med. Res. Intern., 14:606-928.

Slid, E. and Horak, P. (2009). Nitric oxide production: an easily measurable condition index for vertebrates. Behav. Ecol. Sociobiol., 63(7):959966 .

Snedecor, G.W. and Cochran, W.G. (1982). Statistical Methods, $8^{\text {th }}$ edn. Ames: Iowa State.

Swamy, A.V.; Gulliaya, S.; Thippeswamy, A.; Koti, B.C. and Manjula, D.V. (2012). Cardioprotective effect of curcumin against doxorubicin-induced myocardial toxicity in albino rats. Ind. J. Pharmacol., 44(1):73-77.

Tobwala, S.; Hsiu-Jen, W.; Carey, J.W.; Banks, W.A. and Ercal, N. (2014). Effects of lead and cadmium on brain endothelial cell survival, monolayer permeability, and crucial oxidative stress markers in an in vitro model of the Blood-Brain Barrier. Toxics., 2(2):258-275.

Tsakiris, S.; Angelo Gianni, P.; Schulpis, K.H. and Starridis, J.C. (2000). Protective effect of 1-phenylalanine on rat brain acetylcholinesterase inhibition induced by free radicals. Clin. Biochem., 33(2):103-106.

Unsal, C.; Kanter, M.; Aktas, C. and Erboga, M. (2013). Role of quercetin in cadmium-induced oxidative stress, neuronal damage, and apoptosis in rats. Toxicol. Ind. Health., 31(12):1106-1115.

Viaene, M.K,;Masschelein, R.; Leenders, J.; De Groof, M.; Swerts, L.J. and Roels, H.A. (2000). Neurobehavioural effects of occupational exposure to cadmium: A cross sectional epidemiological study. Occup. Environ. Med., 57:19-27.

Wendell, P.L. (1990). Measurements of oxidized glutathione in the perfused rat heart. Biochem. J., 117(4):661-665.

Whittemore, A.S.; DiCiccio, Y. and Provenzano, G. (1991). Urinary cadmium and blood pressure: Results from the NHANES II survey. Environ. Health Persp., 91:133-140.

WHO, (1992). Environmental health criteria 134, Cadmium, Cited as: http://www.inchem.org/documents/ehc/ehc/ehc134.htm

Zalups, R.K. and Ahmad, S. (2003). Molecular handling of cadmium in transporting epithelia. Toxicol. Appl. Pharmacol., 186(3):163-188. 